\title{
Evidence of Variable Gender Role in Defining Language Change Leadership in Syrian Arabic
}

https://doi.org/10.33806/ijaes2000.22.1.8

\author{
Rania Habib \\ Syracuse University, USA
}

Received on 3.2.2021 Accepted on 25.7.2021 Published on 1.1.2022

\begin{abstract}
This study aims to present evidence of gender variability among leaders of language change across different sociolinguistic variables, five phonological variables ( $a$ consonant and four vowels) and a discourse variable in Syrian Arabic, within the same speech community. Employing a sociolinguistic variationist approach and comparing children to adults yielded different gendered linguistic behavior. Children show the same dramatic gendered linguistic difference as adults regarding the variable (q), with males using much more rural [q] than urban [?] than females. Regarding the vowel variables, children dramatize their gendered linguistic difference much more than adults; boys show much higher use of the rural vowels than girls compared to the difference between men and women. This pattern is reversed in the discourse variable (yaSni) 'that is/I mean'; the gendered linguistic difference is more dramatic among adults than it is among children, and gender effect diminishes in the linguistic distribution of the variable. This multidirectionality in gender effects bears implications for sociolinguistic variationist research. Variables indexed to urban refinement/prestige and social meanings such as femininity/masculinity are more likely to be led by females than males. Conversely, variables that lack these types of social/gender identification indexicality, regardless of whether they are phonological or discursive, do not follow the same pattern of leadership.
\end{abstract}

Keywords: gender leadership variability, indexicality, multidirectionality, rural, urban, Syrian Arabic

\section{Introduction}

Generally, women are considered the leaders in most linguistic changes. According to Labov (2001:501), "in the good majority of linguistic changes, women are a full generation ahead of men." This includes changes that involve diffusion or spread of urban features to rural areas (e.g., Habib, 2016a). Conversely, men often express solidarity with their member group or social network and strong connections with their local identity by maintaining a local feature at a much higher rate than women (e.g., Milroy and Milroy, 1985; Habib, 2014). However, in tight social networks and a few professionally or socially forced situations, women have also been found to express linguistic solidarity and/or maintain the local or traditional features (e.g., Milroy and Milroy, 1985; Walters, 1991; Al-Essa, 2009). These varying findings are drawn from culturally and linguistically diverse communities and many of them are based on English speaking communities, with a few focusing on other western languages or nonwestern speech communities. With this backdrop, the following research 
questions arise:

1. Is the linguistic behavior of males and females from one tight-knit Arabic-speaking Syrian community consistent across different sociolinguistic variables?

2. How does this gendered linguistic behavior fit within the generalizations made by previous studies?

Motivated by these questions, this study explores the gendered linguistic behavior in everyday speech of a large representative sample, 72 speakers (50 children and 22 adults), from the tight-knit village of Oyoun Al-Wadi in Syria. The linguistic behavior of males and females from the older and younger generations is compared across six sociolinguistic variables. Five of these variables are phonological and are affected by the diffusion of urban features to rural areas in Syria. One of the phonological variables is a consonant, the voiceless uvular stop qaf (q) (realized as the rural [q] or the urban glottal stop [?]). The other four variables are the vowels (o), (o:), (e), and (e:), which are realized as the rural [o], [o:], [e], and [e:] and the urban [a], [a:], [a], and [a:], respectively. The sixth variable is the posited discourse variable (yaSni) 'I mean/that is' which can take the form of either one of the discourse markers (DMs) yaSni or Pinnu, which can be used interchangeably in the same discoursal context. The findings of all six variables' gendered linguistic behavior are compared to each other to answer the raised research questions.

The comparison will show that we observe age and gender differences in most of these variations, but these differences are not always unidirectional; they may differ from one variable to another, from one age group to another, and from one generation to another. The multidirectionality in gender effects presents evidence of gender variability among leaders of language change across different sociolinguistic variables even within the same tight-knit speech community. In addition, variables that are indexed to urban, and are thus perceived as more prestigious or refined, are more likely to be led by females than males, whereas variables that do not have the same indexicality (Eckert, 2008) or are not associated with urban, regardless of whether they are phonological or discursive, do not follow the same pattern of leadership. The comparison among the mentioned variables will also highlight the influence such diverse associations have on children who often fail to replicate the exact linguistic behavior or frequencies of the community or caregivers, represented by the parents and mothers, respectively.

\subsection{Overview of previous research}

Previous research often considered the primary caregiver as the most influential person in the initial stage of a child's speech development (e.g., Labov, 2010:8; Smith, Durham and Richards, 2013). However, it has also been observed that children can deviate from their caregivers' speech and adopt the most common or acceptable speech by the community (Labov, 2010) or the speech of their peers (e.g., Chambers, 2002).Furthermore, children can change their speech based on the identity they identify with (Wolfram, Carter and Moriello, 2004) and can be 
sensitive to the social meanings of variants (Andersen, Brizuela, Dupuy and Gonnerman, 1999), associating certain variants with certain social groups or categories (Hirschfeld and Gelman, 1997), employing this gained knowledge in their own speech.

Interestingly, studies that explored the influence of the caregivers' input on the child's variable linguistic output yielded conflicting results between correlation (e.g., Foulkes, Docherty and Watt, 2005; K. Miller, 2013) and lack of correlation between the parents' input and children's variable output (e.g., Poplack, 1978; Smith et al., 2013). Likewise, conflicting results emerged from studies that examined gendered linguistic differences between boys and girls. Some studies showed that children as early as18-24 months old display gendered linguistic differences (e.g., Hill and Flom, 2007). Other studies (e.g., Roberts, 1997) did not find gendered linguistic differences between boys and girls in the early stages of development, suggesting that gendered linguistic differences develop after becoming aware of the different gendered social roles in society.

Gender-differentiated linguistic patterns are very common in language variation and change. In western-speaking speech communities, three principles have been established in this regard based on the findings of numerous studies (Labov, 2001:261-293). First, in stable linguistic variation, where no change is occurring, "women show a lower rate of stigmatized variants and a higher rate of prestige variants than men" (Labov, 2001:266). For example, Trudgil's (1972) study of the (ing) variable confirms this principle, where women use the standard variant [ii] more than men who use the non-standard variant [in] more. Second, in linguistic changes from below, women are the leaders of change; "women use higher frequencies of innovative forms than men do" (Labov, 2001:292). These changes occur below the level of consciousness, i.e., incrementally within the system through internally slightly modified parent-to-child transmission (Labov, 2007). The Northern Cities Vowel Shift of Northern America provides an excellent example of these changes from below (Labov, 2007). Third, in linguistic changes from above, women are also the leaders of change, adopting "prestige forms at a higher rate than men" (Labov, 2001:274). An example of a change from above is the linguistic shift in Oberwart from local Hungarian to German, led by young women who reject peasant life and status, symbolized by Hungarian (Gal, 1978). People are conscious of these types of changes from above, which include diffusing changes that result from adult contact with members external to their speech community. The spread of urban features to rural regions is considered a diffusing change from above. Such a spread occurs because people are usually conscious of the social meanings associated with the urban sounds that are being adopted.

Gendered linguistic differences have also been observed in different Arabic varieties (e.g., Abd-el-Jawad, 1986; Walters, 1991). However, given the diglossic situation in the Arab world, the western everyday speech divide between standard and nonstandard forms does not apply in the same way. Standard in Arabic refers to the high language of the Qur'an, writing, reading, sermons, and formal speeches and situations (Ferguson, 1959; Ibrahim, 1986). Nonstandard refers to 
spoken varieties, which may have different social evaluations and prestige. In Arabic, urban and prestigious forms correspond with what is considered standard in the west, and rural or local forms correspond with what is considered nonstandard. In most cases, Arab women show higher use of urban or prestigious forms, whereas men show higher use of rural, local or less prestigious forms (e.g., Daher, 1998; C. Miller, 2005). The gendered linguistic differences are sometimes attributed to associating certain variants with masculinity and femininity (e.g., Habib, 2016a). Sometimes, they are attributed to strong connections with local identity (e.g., Habib, 2016b, 2017b) or heritage, as in the case of Jordanian men who maintain their use of the traditional [g] variant of the variable (q) despite the higher use of the incoming Palestinian urban variant [?] by Jordanian women (AlWer, 2007).

In other cases, where social restrictions and isolation are imposed on Arab women, they tend to be more conservative and preserve their traditional or local variants. For example, Walters (1991) found that older women in the small Tunisian town Korba maintained the use of the stigmatized raised variant of the variable ( $\varepsilon$ :). Likewise, Al-Essa (2009) found that older Najdi women were more conservative than older men and middle-aged and younger women in maintaining the traditional Najdi dialect features in a contact situation with the majority Hijazi dialect in the city of Jeddah. These findings diverge slightly from the generalizations formulated about the gendered linguistic behavior of westernspeaking speech communities in which "[w]omen conform more closely than men to sociolinguistic norms that are overtly prescribed, but conform less than men when they are not" (Labov, 2001:293). These divergent cases among others in the Arab world motivate further investigation into the gendered linguistic norms in Arabic-speaking communities beyond those in which isolation or social communication restrictions are prevalent. Hence, this study focuses on gendered linguistic behavior across a few sociolinguistic variables in a tight-knit Arabicspeaking community with high contact with urban centers and open communication and interaction between the sexes and the external world.

\subsection{Overview of location: Oyoun Al-Wadi}

Oyoun Al-Wadi (Figure 1) is a majority Christian village located in the central western part of Syria, within 60-70 kilometers from three major urban centers: Hims, Tartus, and Hamah. Its dialect shares many linguistic features with the northern part of Lebanon particularly the vowels. Sharing these features is ascribed to two reasons. First, it is close to the Lebanese border and within 75 kilometers (i.e., 51 miles) from the major Lebanese city Tripoli that is known to use similar vowels, such as the emphaticized vowel /a:/ that is assigned similar qualities to the round vowel [o:] (Al-Nassir, 1993:103). Second, it is believed that the rural [q] and vowel variants arrived with the father and founder of the village around A.D. 1700, Sabiq Suleiman Ma'louf, who is originally from Kafr 'Oqab (Al-Ma'louf, 2008), a village located in what is now the Matn District of Mount Lebanon Governorate that is centrally located in Lebanon. 


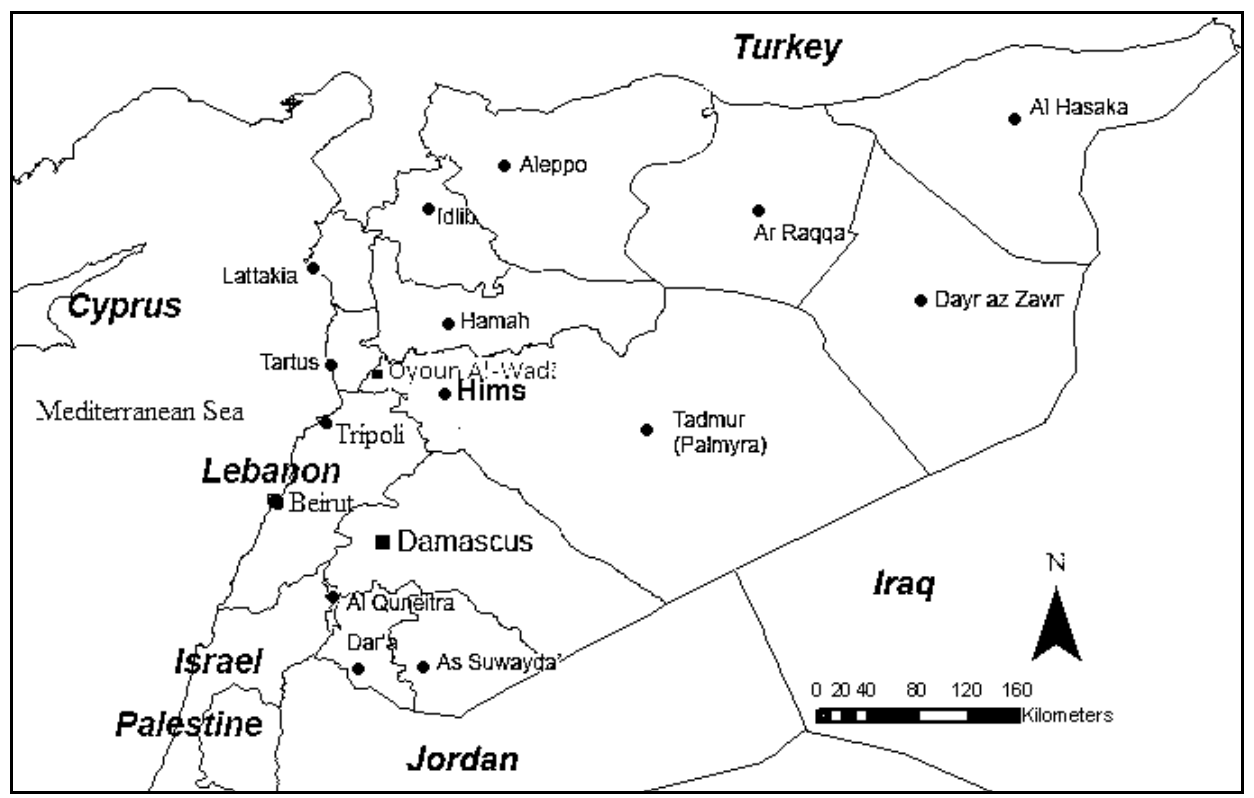

Figure 1. Map of Syria.

Oyoun Al-Wadi's central location, cool mountains, beautiful landscape, and luscious nature attract tourists from urban areas particularly in the summer. For the longest while, the villagers tried to preserve it from foreign/external influence, including preserving property ownership, endogamous marriages, and the use of local linguistic features, ridiculing villagers who imitate urban speech (Habib, 2014). However, increased contact with tourists in the past forty-fifty years, among other factors, such as exogenous marriages, migration to urban centers for college education and white-collar jobs, and increased commuting between urban and rural centers led to major infrastructural, social, and linguistic changes. These changes affected the fabric and demographics of the village community that can be described now as being highly heterogeneous because currently the majority of women are non-local and come from diverse backgrounds; they come from various urban and semi-urbanized places where the supralocal urban form [?] is prevalent. ${ }^{1}$ Despite all of these changes, people, specifically males, remain very loyal to their village and proud of it, often expressing sentimental attachment to the village and projecting a very strong sense of local identity either through their speech or through memorable anecdotes of historical events or victorious or chivalrous acts of men from the village (Habib, 2014).

\section{Data analysis and comparisons}

The data are based on the naturally occurring speech of 72 participants who were informally interviewed in spring 2010 for 30-60 minutes in the presence of one or more friends and/or one or more family members to elicit the most naturalistic, everyday speech. The 72 participants consist of 22 adults (11 married couples ages 29-57) and 50 children ( 25 males and 25 females) who are divided almost equally 
into four age groups $(6-8,9-11,12-14$, and 15-18), based on different developmental and school stages in their lives, with an almost equal number from each gender in each age group. The analysis utilizes numerous variationist quantitative and qualitative methods that were applied to the various variables explored in this paper (for more details on data collection and statistical methods, see Habib, 2014, 2016a, 2016b, 2017a, 2017b). Our main concern in this paper is to compare and contrast the gendered linguistic differences observed in these various studies to show that inconsistencies and multidirectional gendered linguistic behavior may exist within the same tight-knit speech community depending on the type of variable, indexicality and/or functionality of variable, the age of the children, and/or belonging to the older or younger generations.

\subsection{Phonological variables: (q), (o), (o:), (e), and (e:)}

The five phonological variables (q), (o), (o:), (e), and (e:) exhibit competing linguistic changes (Habib 2014, 2016a, 2016b). While there are diffusing changes in progress towards the urban variants [?], [a], [a:], [a], [a:] respectively, local identity and masculinity play significant roles in reversing these changes among boys in the village towards much higher use of the rural variants [q], [o], [o:], [e], [e:], respectively. Hence, these reverse changes cannot be attributed to diffusion (Labov, 2007) as in the urban changes, because these changes come from within the village, not through adult contact outside the community. Rather these reverse changes are driven by internal peer pressure and ridicule, assigning males who use urban forms descriptions such as weak, effeminate, and Mishtawe that is a derogatory term derived from the name of the historically rival connecting town, Mashta Al-Helou whose males and females use the supralocal urban form [?] exclusively. This derogatory term became popular in Oyoun Al-Wadi whose males often defeated males from Mashta Al-Helou in conflicts and fights. This historical rivalry is asserted in Oyoun Al-Wadi by staying linguistically distinct especially by males who view themselves as strong, defiant, and protective of their village, women, dignity, and property. Hence, people in Oyoun Al-Wadi, particularly males, associate the use of urban forms, particularly the glottal stop [?], with weakness and femininity and associate the rural forms, particularly the voiceless uvular stop [q], with masculinity, toughness, and local identity. Indexing these variants with these social meanings is highly embraced by boys and girls in the village, leading to much higher use of the rural forms by boys and maintenance of the urban forms by girls.

In other words, the encroaching urban variant [?] started gaining different social meanings to prestige and refinement due to rivalry conflicts with males from the neighboring town. The new social meanings are weakness, fragility, and femininity, characteristics that are highly problematic for boys in the village. However, these added meanings do not pose any problem for girls who feel no social pressure to change their initially acquired supralocal forms from their caregivers partially because they are viewed in the community and by boys as weak and requiring protection. This in turn intensified the social meanings of [q] as local, tough, and masculine. Numerous comments from both genders and both 
generations show that [?] is gentler, softer, and more appropriate for girls than [q]. For example, Rachel (13-year-old girl) said "I told my mother the other day I like the qaf more, but she said the ?af is nicer for girls... when qaf is used sometimes by the girl, it is too heavy and ugly." 2 This is just one example of the linguistic ideology that exists in this tight-knit community, "i.e., girls should refrain from the use of [q] and it is acceptable if boys use it" (Habib, 2016b:49). In speakers' own words [q] is "heavy", "ugly", "rough", and "masculine" among other similar terms, while [?] is "soft", "feminine", "refined", and "gentle" among other similar terms (Habib, 2016b:48). A similar ideology and terminology are expressed regarding the vowel variables (Section 2.1.2). In this sense, "the community is not only setting norms and expressing preferences and expectations of girls and boys but also projecting a prominent difference between the two genders" (Habib, 2016b:49).

Although all five variables have rural and urban variants and the rural variants of all five variables are highly indexed to local identity, gender emerged as statistically significant for both the older and younger generations regarding the variable (q) but was only significant for the younger generation regarding the vowel variables.

\subsubsection{The variable(q)}

As mentioned previously, the consonant variable $(\mathrm{q})$ is realized as the rural $[\mathrm{q}]$ or urban [?] in the same phonological environment, e.g., [qalam]/[?alam] 'pen'; [baqra]/[ba?ra] 'cow'; [waraq]/[wara?] 'papers'. The [?] is an urban variant that has been spreading widely in rural Syria as well as other regions in the Arab world (e.g., Abd-el-Jawad, 1986; Al-Wer, 2007). Its association with urbanization makes it a transformative variant in several ways particularly in terms of how urbanization affects and transforms rural Syria, an aspect that may have ambivalent effect on rural people and particularly opposite genders.

Table 1. Distribution of (q) by gender and generation.

\begin{tabular}{lllll}
\hline Gender & $\begin{array}{l}\text { N of } \\
\text { speakers }\end{array}$ & N of $[\boldsymbol{q}]$ & $\mathbf{\%}$ of $[\boldsymbol{q}]$ & Total of $[\boldsymbol{q}]$ and \\
Boys & 25 & 861 & 39 & 2207 \\
Girls & 25 & 226 & 8 & 2916 \\
Total of children & $\mathbf{5 0}$ & 1087 & $\mathbf{2 1}$ & 5123 \\
Fathers & 11 & 1787 & 85 & 2095 \\
Mothers & 11 & 177 & 7.5 & 2357 \\
Total of parents & $\mathbf{2 2}$ & 1964 & $\mathbf{4 4}$ & 4452 \\
Total of all & $\mathbf{7 2}$ & 3051 & $\mathbf{3 2}$ & 9575 \\
speakers & & & & \\
\hline
\end{tabular}

Table 1 presents the distribution of the variable (q) in the speech of the 72 speakers. It shows that the variant [?] is used $68 \%$ and more prevalent in the community than the local [q]. However, the use of [q] is more than double in the older generation compared to its use in the younger generation. This double use is 
due to the much higher use of [q] by men, $77.5 \%$ more than women, which is a major difference between the two genders. A similar difference is observed between boys and girls; boys use [q] $21 \%$ more than girls.

The presence of generational and gender differences signals a change in progress towards the urban form [?] (Habib, 2016a, 2016b, 2017b). This change is led by the majority non-local women and advanced by girls. A closer look at the distribution of [q] between boys and girls in the four age groups (Figure 2) shows that both boys and girls in the youngest age group rarely use the rural [q]. This categorical or almost categorical use of [?] is maintained in the girls' three older age groups despite a couple of minor exceptions discussed below. A stark difference is observed between boys and girls in the three older age groups. Boys increase their use of [q] to almost $40 \%$ in the age group 9-11 and to more than $60 \%$ in the age group $12-14$, dropping to about $45 \%$ in the age group $15-18$. This observed S-curve pattern across the boys' four age groups signals a different change in progress from the one towards the urban [?]. It is an accelerating reversed change towards the local [q], occurring exclusively among boys after age eight. By increasing their use of the rural [q], the boys, as aforementioned, are asserting a local and masculine identity and avoiding ridicule and effeminate description from their male peers by avoiding the use of the urban [?]. Applying binary regression tests, gender emerged as statistically significant between both the younger $(p=.000)$ (Habib 2016a) and the older $(p=.000)$ (Habib, 2017b) generations.

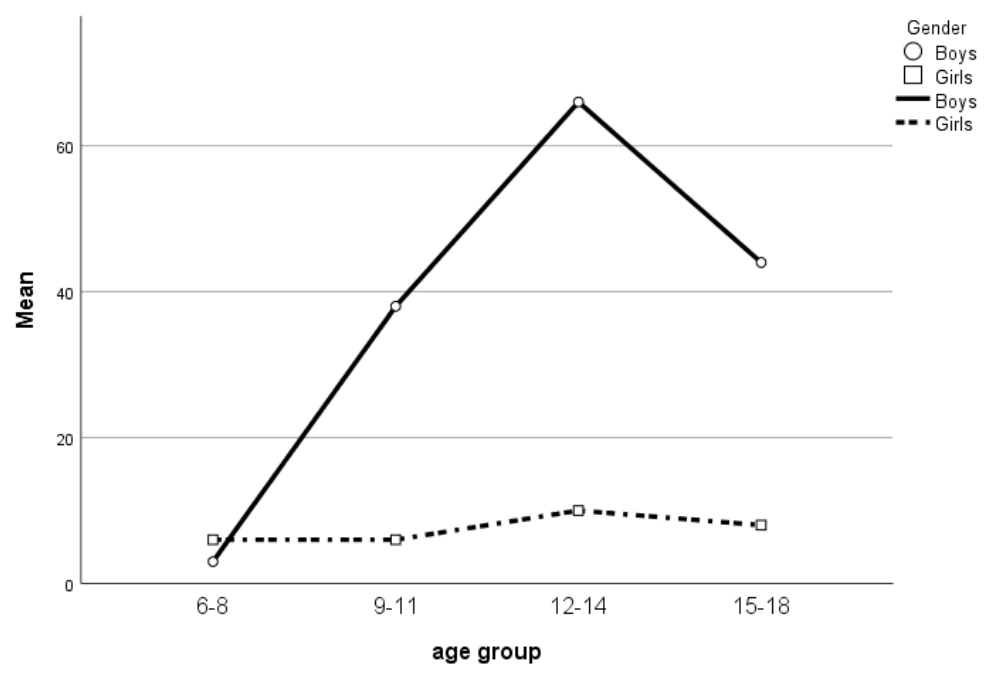

Figure 2. Distribution of [q] in children's speech by age group and gender.

Nonetheless, comparing children's speech to that of their parents and using paired-samples $t$-tests that include correlation tests yielded statistically significant differences and lack of correlation in the frequency of use of [q] not only between fathers and daughters (Correlation: $r=.341, p=.334$; Difference: $t=11.082, p=.000$ ) 
but also between fathers and sons (Correlation: $r=\cdot 363, p=\cdot 272$; Difference: $t=4.547, p=\cdot 001$ ) (Habib 2017b), mothers and sons (Correlation: $r=.401, p=.222$; Difference: $t=-2.345, p=.041$ ) (Habib, 2017b), and some mothers and daughters (Figure 3), although there is a general positive correlation between mothers and daughters $(r=.817, p=.004)$ and negligible difference $(t=.907, p=.388)$. For example, Figure 3 shows that the two 6-year-old boys Adan and Anis [boys and girls are ordered from youngest to oldest on the right and left sides of the chart respectively] sound more like their mothers and girls than their fathers, whereas Maher (14-year-old), Peter (15-year-old), and Kamal (18-year-old) sound more like their fathers. Most boys nine years and older show much higher use of [q] than girls and their mothers. However, their use of [q] is not as high as that of their fathers. Most women show categorical or almost categorical use of [?] except for one local woman, mother of Rachel and Peter. Likewise, most girls show categorical or almost categorical use of [?] except for Rachel (13-year-old) who shows $19 \%$ use of [q]. Although, both her parents are local and categorical users of [q], her much lower use of [q] than her parents indicates that she aligns herself and her speech much more with her female peers than with her parents or mother. At the same time, her slightly higher use of [q] than her female peers marks her as more local than other girls (cf. De Houwer, 2003).

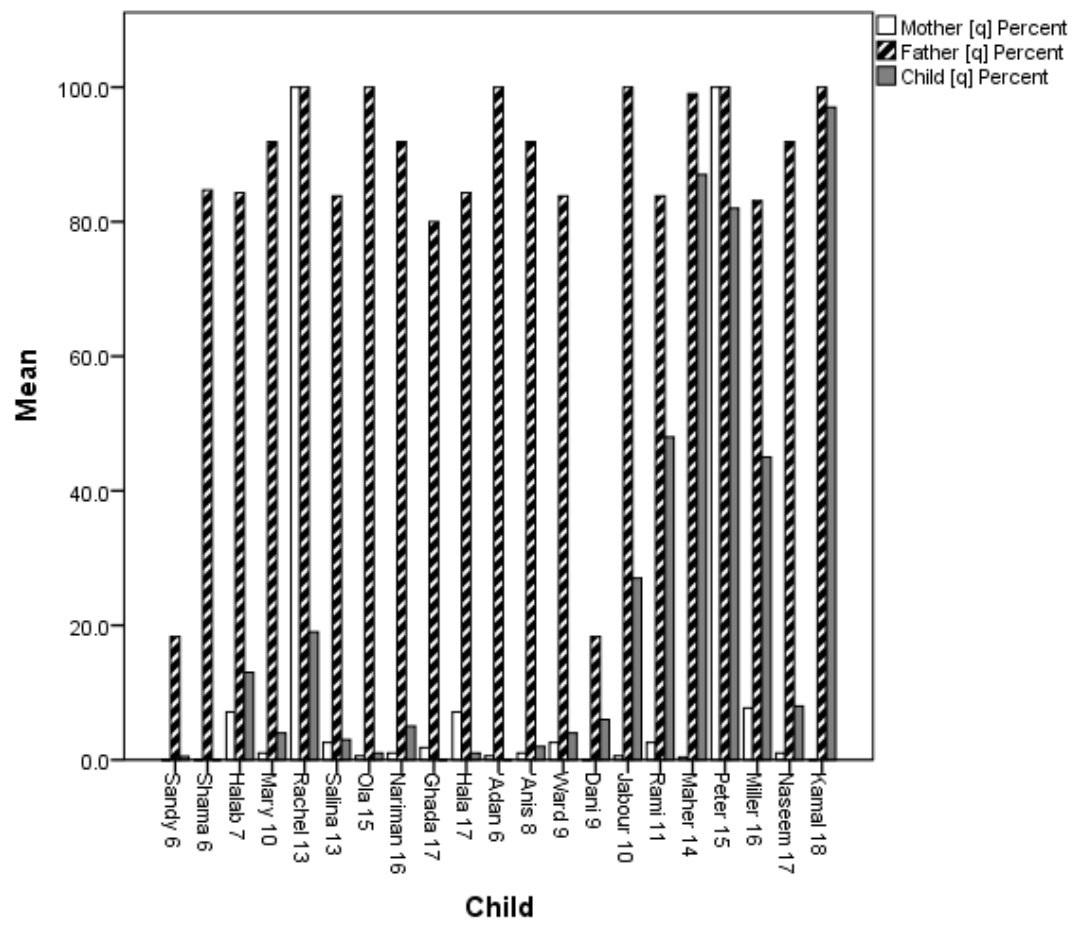

Figure 3. Comparison of the percentages of $[q]$ between individual children and their parents. 
These differences and the very low usage of [q] by both boys and girls in the early stages of their speech development indicate that children initially acquire the majority non-local mothers' supralocal form. They do not acquire the variation that exists in their immediate environment. The variable gendered pattern in the community is acquired later, but it is not acquired faithfully as their frequencies differ from that of their parents or caregivers (Habib, 2017b). After age eight, they start realizing and accepting the gendered linguistic differences in their community, the social meanings associated with each form, and the importance of certain forms for projecting gendered and spatial identities (Habib, 2016b). This realization leads to more rural forms by boys and retention of girls' urban forms. Thus, the variation observed in the later stages of these children's lives is not a byproduct of the early stages of acquisition (Roberts, 2005; Foulkes et al., 2005). Rather, it is driven by socio-psychological factors such as social meanings and local identity and "later acquisition of superposed dialects" (Labov, 2013:247), which coincide in this study with the rural form that is superposed on the urban form in the boys' speech. In this sense, transmission (Labov, 2007) plays a role only in early childhood, and peer pressure, local identity, and the social meanings indexed to the rural and urban variants play a more important role after age eight.

The rare exceptions of slightly higher use of [q] among a couple of girls in the village can be attributed to similar factors to those affecting boys: strong connection to their local identity (e.g., Rachel (13-year-old) uses [q] 19\% (Figure 3)) and trying to project masculinity or toughness in their speech in addition to strong attachment to their local identity (e.g., Salam (15-year-old) uses [q] 25\% (Habib, 2016a)). These examples indicate that [q] is indexed to local identity, masculinity, and toughness (Habib 2016b). Hence, using [q] does not necessarily mean being a male/boy group member. Rather, it mainly signifies locality and toughness. Having this symbolic significance, the rural variants maintain their vitality against the pressure of urbanization by virtue of their ability to differentiate the local from the urban, much like Ocracoke's males' preference for the non-standard weren't due to its symbolic significance to their islander identity, an identity with which males associate (Schilling-Estes and Wolfram, 1994:287288).

\subsubsection{The variables (o), (o:), (e), and (e:)}

Moreover, the variables (o), (o:), (e), and (e:) are realized as either the rural [o], [o:], [e], and [e:] or the urban [a], [a:], [a], [a:] respectively in the final syllable of a word including if it is an inflectional morpheme. The round vowels, [o] and [o:], and 'imala vowels, [e] and [e:], in the variety of Oyoun Al-Wadi are phonologically, morphologically and lexically conditioned (Habib 2012), which is beyond the scope of this study. Representative examples of each variable are

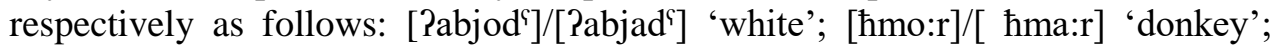
[samak]/[samek] 'fish'; [kte:b]/[kta:b] 'book'. Tables 2 and 3 present the distributions of these four variables. Similar patterns to (q) are observed regarding these four variables. Urban vowels are more prevalent in the community. Parents use higher percentages of the rural vowels than children, and both men and boys 
use more rural vowels than women and girls respectively.

Table 2. Distribution of (o) and (o:) by gender and generation.

\begin{tabular}{lllllll}
\hline Gender & $\begin{array}{l}\mathbf{N} \text { of } \\
{[\mathbf{o}]}\end{array}$ & $\begin{array}{l}\text { \% of } \\
{[\mathbf{0}]}\end{array}$ & $\begin{array}{l}\text { Total of [o] } \\
\text { and [a] }\end{array}$ & $\begin{array}{l}\mathbf{N} \text { of } \\
{[\mathbf{0}:]}\end{array}$ & $\begin{array}{l}\text { \% of } \\
{[\mathbf{0}:]}\end{array}$ & $\begin{array}{l}\text { Total of [o:] } \\
\text { and [a:] }\end{array}$ \\
\hline $\begin{array}{l}\text { Boys } \\
\text { Girls }\end{array}$ & 72 & 27 & 666 & 105 & 26 & 403 \\
$\begin{array}{l}\text { Total of } \\
\text { children }\end{array}$ & 72 & 9 & 806 & 24 & 6 & 376 \\
$\begin{array}{l}\text { Fathers } \\
\text { Mothers }\end{array}$ & 250 & $\mathbf{1 7}$ & 1472 & 129 & $\mathbf{1 7}$ & 779 \\
$\begin{array}{l}\text { Total of parents } \\
\text { Total of all 72 } \\
\text { speakers }\end{array}$ & 349 & 48 & 479 & 106 & 44 & 239 \\
\hline
\end{tabular}

Table 3. Distribution of (e) and (e:) by gender and generation.

\begin{tabular}{lllllll}
\hline Gender & $\begin{array}{l}\mathbf{N} \text { of } \\
{[\mathbf{e}]}\end{array}$ & $\begin{array}{l}\text { \% of } \\
{[\mathbf{e}]}\end{array}$ & $\begin{array}{l}\text { Total of [e] } \\
\text { and [a] }\end{array}$ & $\begin{array}{l}\mathbf{N} \text { of } \\
{[\mathbf{e}:]}\end{array}$ & $\begin{array}{l}\text { \% of } \\
{[\mathbf{e}:]}\end{array}$ & $\begin{array}{l}\text { Total of [e:] } \\
\text { and [a:] }\end{array}$ \\
\hline $\begin{array}{l}\text { Boys } \\
\text { Girls }\end{array}$ & 578 & 37 & 1566 & 1226 & 44 & 2768 \\
$\begin{array}{l}\text { Total of } \\
\text { children }\end{array}$ & 373 & 24 & 1537 & 865 & 28 & 3063 \\
$\begin{array}{l}\text { Fathers } \\
\text { Mothers }\end{array}$ & 951 & $\mathbf{3 1}$ & 3103 & 2091 & $\mathbf{3 6}$ & 5831 \\
$\begin{array}{l}\text { Total of parents } \\
\text { Total of all 72 } \\
\text { speakers }\end{array}$ & 2425 & 81 & 1760 & 1552 & 68 & 2283 \\
\hline
\end{tabular}

Interestingly, in the case of the four vowel variables, children go a step further in their gendered linguistic behavior (Habib 2014, 2017a). Taking the vowel (o) as an example, Figure 4 shows a sizeable difference between boys and girls in the use of the rural variant [o]. All girls of all ages show categorical or almost categorical use of the urban variant [a], i.e., less than $10 \%$ use of [o]. In contrast, boys who initially start at an almost similar level to girls in the age group 6-8 show a spike in their use of [o] to almost $40 \%$ in the age group 9-11 with a slight drop to the range of $25 \%$ in the two older age groups. Their pattern of use of the [o] vowel is like their pattern of use of [q]. They are reversing their use of the urban [a] and increasing their use of the rural [o] with age. Thus, as in the variable (q), there is a reverse second change only among boys towards higher use of the rural forms in the face of the first diffusing change in progress towards the urban forms led by women and advanced by girls. The statistically significant gender difference between boys and girls (for (o) $p=.000$; for (o:) $p=.000$; for (e) $p=.009$; for (e:) $p=.007$ ) (Habib 2014) in addition to the increase of use of the rural forms with age among boys confirms this reverse change in progress. 


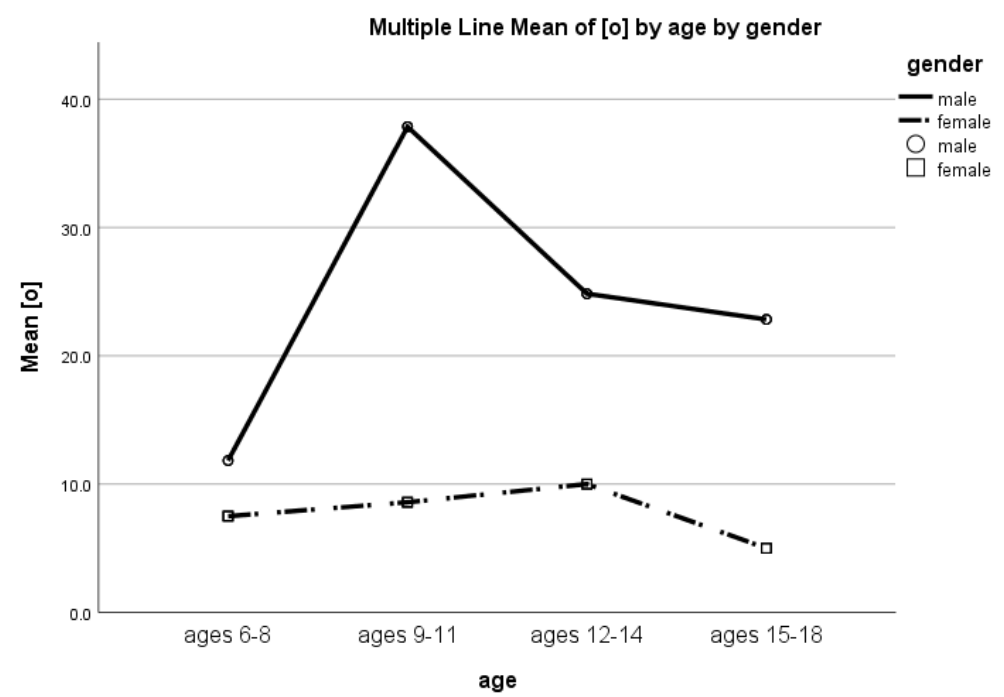

Figure 4. Distribution of [o] in children's speech by age group and gender.

Furthermore, paired-samples $t$-tests that include correlation tests showed mostly lack of correlation and statistically significant differences in the use of all vowel variables between children and adults, mothers and daughters, mothers and sons, and fathers and sons (Habib, 2017a). Results are not included to conserve space. Figure 5 shows that boys [boys and girls are ordered from youngest to oldest on the right and left sides of the chart respectively] use more [o] than girls but their use is lower than that of their fathers. Girls show very limited use of [o] compared to not only the fathers, but also the boys and the mothers. Fathers use [o] slightly more than mothers. These observations indicate that children are acquiring the immediate environment gendered linguistic pattern but are not acquiring the exact frequencies of female and male adults in the community or their caregivers. The observations in Figure 5 are supported by the emergence of gender as a statistically significant predictor for children only (for (o) $p=.000$; for (o:) $p=.000$; for (e) $p=.009$; for (e:) $p=.007$ ) (Habib, 2014), but not for adults (for (o) $p=.080$; for (o:) $p=.883$; for (e) $p=.329$; for (e:) $p=.260$ ) (Habib, 2017a). The statistically significant difference in the linguistic behavior between girls and boys against the non-significant difference between mothers and fathers indicates that children are exaggerating the gendered linguistic patterns of the vowels in their community and creating a larger gap between boys and girls or a more pronounced differentiated gendered linguistic behavior than that of adults. 


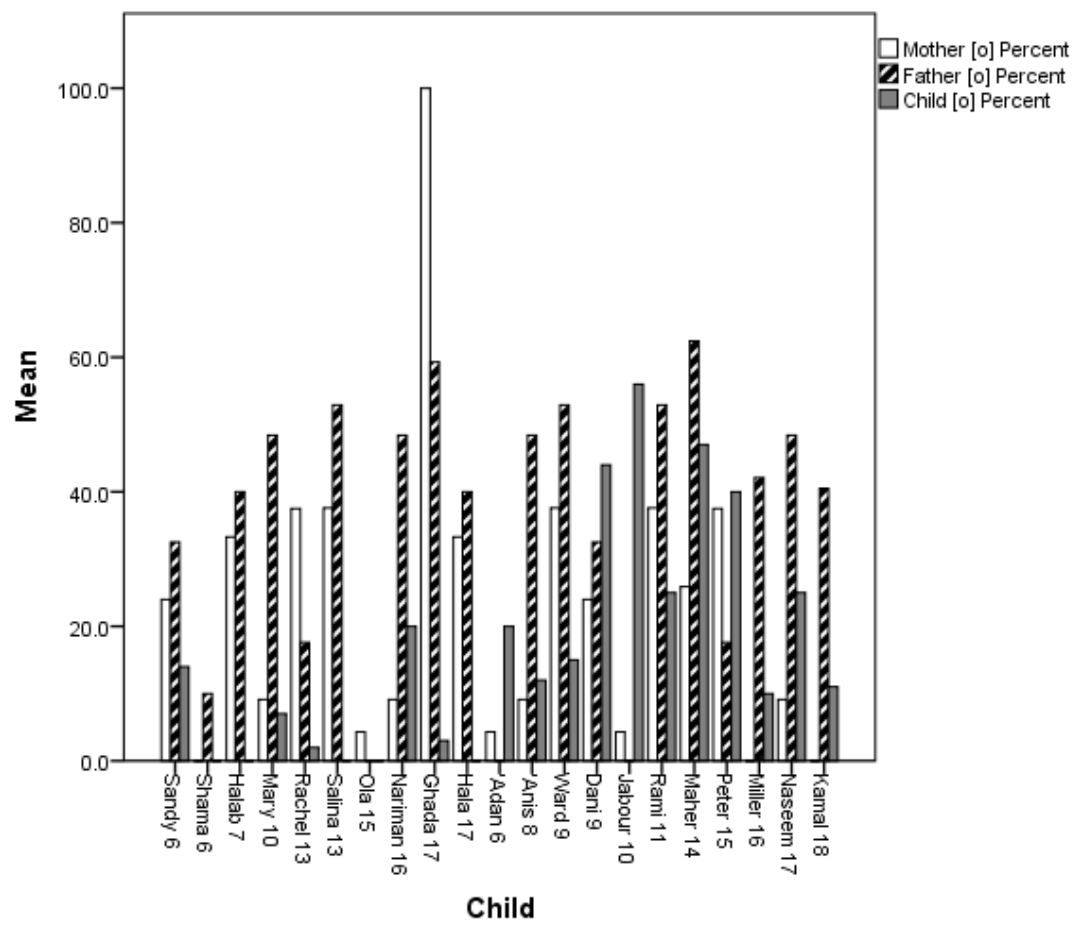

Figure 5. Comparison of the percentages of [o] between individual children and their parents.

In other words, while boys and girls show a similar pattern to men and women in their use of the vowels, the linguistic difference between them is much more dramatized than the linguistic difference between adults. This dramatic linguistic behavior parallels their and the community's gendered linguistic behavior in the case of the variable(q). It is developed and advanced by both boys and girls to maintain a linguistic and social distinction that is driven by the prevalent ideology in the community: sounding refined requires changing the heavily rural features to their equivalent urban features, as expressed by Marwan (49-year-old father) among others, "our dialect is slightly rough... One may want to change some words. For example, one should not 'round' a lot...for example, saying [?aћmor] 'red'...say [?aћmar]...For example, we should not say [be:b] 'door'... Say [ba:b]." This ideology among other societal aspects enables boys and girls to observe noticeable differences in gender roles in the community and a strong distinction between local and urban identities associated with the rural and urban forms. Hence, as in the case of (q), to advance an urban, refined, sophisticated outward appearance, girls maintain much lower rates of the rural vowels even lower than their caregivers, and boys increase their use of the rural vowels and use much higher rates than girls to assert their local identity. This suggests that children are highly aware of the different phonological variations in their environment and the significance of certain sounds to projecting specific gender and spatial identities, and they can manipulate these variations accordingly. 
This further indicates the influence of socio-psychological factors in their observed inter-speaker variation and their sociolinguistic competence and agency's immense development.

\subsection{The discourse variable (yaSni)}

In this study, (yaSni) 'I mean/that is' is posited as a functionally defined variable, defined as all possible exchangeable forms used as discourse markers (DMs), whether used as fillers, for clarification, for turn taking, for repair, etc. The interchangeable DM syaSni and Pinnu in the same discourse context are posited as the exchangeable realizations of this discursive variable, e.g., ?ana:, yaSni/Pinnu, ma: bhibb lhaki: kti:r 'I, that is/I mean, don't like talking a lot.' These two DMs have traditionally different meanings and syntactic and pragmatic functions. yaSni is historically a third person singular verb that literally means 'he/it means', which has grammaticalized into an impersonal DM and has been examined as such in the literature (e.g., Al-Batal, 1994; Mughazy, 2003). On the other hand, Pinnu has mainly been described or analyzed as a complementizer (e.g., Cowell, 1964:449451, 541-547; Habib, 2009). Exceptionally, Germanos (2010) explores its development into a DM. However, Germanos (2010) did not observe or explore a possible interchangeability with yaSni. Notwithstanding, Owens and Rockwood (2008) and Rieschild (2011) briefly hint at the possibility that the two words can compete for the same semantic space and pragmatic functions, such as repair, holding a turn, hedging a response, elaborating, explaining, and clarifying.

\subsubsection{Social distribution of (ya9ni)}

Competing uses of these two DMs yaSni and Pinnu are found between males and females in both the older and younger generations and within the children's different age groups (Habib 2021). While the use of yaSni and Pinnu seems balanced at $52 \%$ in the data set, Table 4 shows that adults use yaSni $32 \%$ more than Pinnu, and men use it $11 \%$ more than women. In contrast, children use Pinnu $22 \%$ more than yaSni and boys use it 5\% more than girls. These competing uses reflect a reversed linguistic pattern between children and adults. This reversed pattern is intriguing and implies, in contrast to the phonological variables discussed above, that not only are these children not acquiring the frequencies of their community faithfully, but they are also following a different pattern of linguistic use from their community, i.e., they are advancing the use of ?innu over $y a$ nni that is preferred by the older generation.

Employing mixed effects binomial logistic regression tests, gender emerged as statistically significant among parents $(p=.033)$, but not among children ( $p=.371$ ), indicating that the younger generation, both boys and girls, prefers a DM that adults disfavor. Initially, there is limited use of Pinnu and more use of yaSni in the youngest age group (Figure 6). The use of Pinnu spikes in the age group 9-11, corresponding with sharp decrease in the use of yaSni in this age group. However, the use of Pinnu and yaSni becomes more balanced in the two older age groups. The highly increased use of the innovative form Pinnu in the age group 9-11 indicates that preadolescents are more sensitive and adoptive of 
innovations than adolescents. This contrasts with the adolescent peak that is espoused in the literature as an indication of a change in progress and a reflection of the age group that is most adapt and shows the highest incrementation of the innovative forms (e.g., Labov, 2001; Holmes-Elliot, 2016). The low use of Pinnu in the initial stage of children's development predictively indicates that children acquire yaSni before Pinnu. This is not surprising given that parents use much more yaSni than Pinnu in their speech.

Table 4. Distribution of yaSni and Pinnu by gender and age.

\begin{tabular}{llll}
\hline Gender & N of yaSni & \% of $\mathbf{y a S n i}$ & Total of $\mathbf{y a S n i}$ and Pinnu \\
\hline Boys & 346 & 40 & 858 \\
Girls & 875 & 45 & 1927 \\
Total of children & 1221 & $\mathbf{4 4}$ & 2785 \\
Fathers & 555 & 72 & 771 \\
Mothers & 554 & 61 & 908 \\
Total of parents & 1109 & $\mathbf{6 6}$ & 1679 \\
Total of all 72 speakers & 2330 & $\mathbf{5 2}$ & 4464 \\
\hline
\end{tabular}

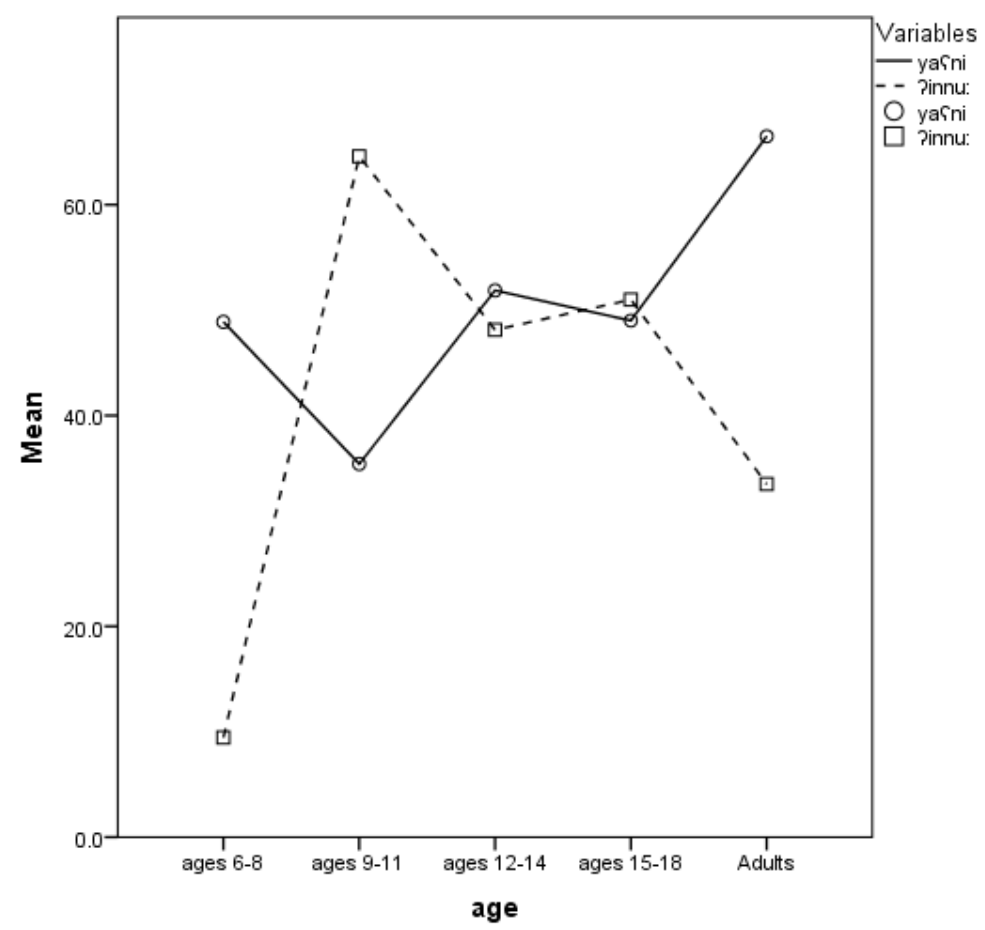

Figure 6. The mean use of yaSni and Pinnu by the different age groups.

The undulating pattern observed among children (Figure 6) could be confused between an age-graded linguistic behavior or a change in progress 
towards the use of Pinnu because of the statistically significant difference ( $p=.015$ ) between the younger and older generations' uses of Pinnu; children use Pinnu 22\% more than adults. However, the gender difference between boys and girls did not emerge as statistically significant, which does not confirm a change in progress analysis in apparent time. It is possible to assume that the observed undulating pattern of use among children and the statistically significant difference between men and women and children and parents as an indication of instability in both the individual and the community. Such assumption accords with Labov's (1994:83) fourth scenario of linguistic change, communal change, and mirrors Buchstaller's (2006) wave-like pattern regarding the use of the quotative $g o$, which is neither a change in progress nor an age-grading pattern. It is merely a wave-like pattern of variation where a variant dips and peaks based on socio-psychological factors.

This further raises questions about what and how socio-psychological factors play a role in children's linguistic use of Pinnu and yaSni. Do children associate certain meanings with these variants as they grow older? There is no evidence that these two variants are associated in any way with urban or rural meanings or identities. It is possible that this behavior is a universal aspect of language whereby children use more innovative DMs than adults as is the case in the increasing use of like in the speech of the younger English-speaking generation, e.g., among Canadian youth (Tagliamonte, 2005), a feature disliked by the older generation.

\subsubsection{Linguistic distribution of (yaYni): Structural position}

Four structural positions of the two DMs yaSni and Pinnu in an utterance in the speech of the 22 adult couples were examined: (1) initial (e.g., yaSni/Pinnu, ma: Ga:mli:n se:r $\chi i t^{\dagger} b i$ 'That is/I mean, they are doing only simple engagement'); (2) medial (e.g., mnihke:, Pinnu/yaSni, mnittife? Ya-fasli 'We talk about, that is/I mean, we agree on something'); (3) final (e.g., btihki:Ina: ktiir, yaSni/Pinnu 'She narrates to us a lot, that is/I mean'); and (4) standalone. This examination shows that Pinnu occurs mostly in medial position (72\%), $26 \%$ in initial position, rarely in final position (2\%), and almost never alone. However, the syntactic position of yaSni seems to be more variable. It occurs $51 \%$ in initial position, $33 \%$ in medial position, $15 \%$ in final position, and rarely stands alone. Hence, medial position favors ?innu and initial and final positions favor yaSni. What is interesting in the structural positioning of these DMs is that gender does not play a role; it did not emerge as statistically significant in the Independent-Samples T-Test (Initial: $p=.178$; Medial: $p=.902$; Final: $p=.666$; Standalone: $p=.290$ ). Both males and females have similar rates in all positions for each DM. In other words, one gender does not favor one position over another for each of the DMs.

This lack of gender effect in the structural positioning of DMs implies that gender plays a role only in determining the frequency of use of each discourse variant, but not its syntactic position. It can play a role in the social distribution of a variable but not its linguistic distribution (cf. Omari and Jaber, 2020). This discovery raises the question about why gender plays a role in certain linguistic aspects such as frequency and not others such as structural positioning. It also 
suggests that certain discourse variants occur in certain linguistic positions more than others because they are associated with specific pragmatic functions more than others, which in turn have higher association with those specific syntactic positions. For example, the favoring of Pinnu in medial position could be due to its higher association with pragmatic functions such as repair or clarification or being used as a hedge or filler, parallel to yaSni if it occurs in a medial position (Dermarker, 2014). However, the favoring of yaSni in the initial position could be due to its higher association with pragmatic functions such as holding or initiating a turn or introducing a clarifying response. The higher use of yasni in final position could also be due to its more frequent use as an assessing (Ghobrial, 1993:47) or commenting element used to indicate the conclusion of a preceding explanation, clarification, or elaboration (Marmorstein, 2016). In this sense, both genders associate each DM with specific semantic functions that are more likely to occur in specific structural positions (Habib, 2021). Hence, they employ them to the same degree in similar positions to express certain semantic and pragmatic functions despite the statistically significant general frequency difference between the two genders.

\section{Conclusions and future directions}

Within the social distribution of the consonant, vowels, and discourse variables, different findings emerged regarding the gendered linguistic behavior of children and adults (Table 5). In the case of the consonant variable (q), gender emerged as statistically significant between both children and adults. The difference between men and women and boys and girls is great and highly noticeable in the community. Boys assert their local and masculine identity by reversing course to much higher use of the rural form [q] after age eight. Although children do not acquire the exact frequencies of their immediate environment or their caregivers, they acquire the dramatic gendered linguistic pattern of their community.

Table 5. Summary of the difference in use of all variables by gender and age.

\begin{tabular}{|l|l|l|l|l|}
\hline & $\begin{array}{l}\text { (q) Social } \\
\text { distribution } \\
\text { Difference }\end{array}$ & $\begin{array}{l}\text { (Vowels) } \\
\text { Social } \\
\text { distribution } \\
\text { Difference }\end{array}$ & $\begin{array}{l}\text { (yafni) } \\
\text { Social } \\
\text { distribution } \\
\text { Difference }\end{array}$ & $\begin{array}{l}\text { (yaSni) } \\
\text { Linguistic } \\
\text { distribution } \\
\text { Difference }\end{array}$ \\
\hline Boys and Girls & Significant & Significant & $\begin{array}{l}\text { Not } \\
\text { significant }\end{array}$ & N/A \\
\hline $\begin{array}{l}\text { Men and } \\
\text { women }\end{array}$ & Significant & $\begin{array}{l}\text { Not } \\
\text { significant }\end{array}$ & Significant & $\begin{array}{l}\text { Not } \\
\text { significant }\end{array}$ \\
\hline
\end{tabular}

In the case of the vowel variables, gender emerged as statistically significant between children only and as not significant between adults. Hence, children dramatize the gendered linguistic pattern of their community, making it parallel to that of the (q) variable. They also do not acquire the exact frequencies of their immediate environment or their caregivers.

In the case of the discourse variable (yaSni), the children show a reverse 
pattern to their parents, using more ?innu than yaSni, and boys using more Pinnu than girls, while women use more Pinnu than men (Habib, 2021). Gender emerged as statistically significant between adults only, not between children, preventing a confirmation of a change in progress towards Pinnu, although the difference between children and adults emerged as statistically significant, indicating that all children regardless of their gender are moving towards higher use of the innovative form Pinnu.

Within the linguistic distribution of the DMs yaSni and Pinnu, gender did not emerge as statistically significant, indicating that gender plays a role only within the social distribution of discourse variables. In other words, the structural position determines which discourse variant is more likely to occur initially, medially, finally, and alone, possibly due to higher association of each of the two DMs with certain pragmatic functions that are mapped more frequently to certain syntactic positions.

The findings of the above investigations challenge theories that indicate that the primary caregiver is the most influential person in the initial developmental stage of a child's speech (Labov, 2010:8; Smith et al., 2013) and theories that children usually adopt the speech that is most common or acceptable by the community (Labov, 2010). The latter is especially challenged by the discourse variable yasni. These findings also pose challenges to the three principles established regarding gender-differentiated linguistic behavior in language variation and change (Labov, 2001). Females are the leaders in the majority of linguistic changes and have higher conformity than men to sociolinguistic norms and innovative or "overtly prescribed" forms. Conversely, the findings show multidirectionality in gender effects, which provides evidence for gender variability among leaders of language change across different sociolinguistic variables even with in the same tight-knit speech community, Oyoun Al-Wadi. While females lead the diffusing urban changes with respect to the consonant and vowel variables, boys lead a reverse change towards the local forms despite behaving like girls and mothers in their initial stages of development. In the case of the discourse variable, despite the statistically significant generational difference between adults and children, a change in progress could not be confirmed due to the reversed patterns of gendered linguistic behavior between adults and children. Mothers show significantly higher use of the innovative form Ріпnu than fathers, whereas boys use Ріпnи 5\% more the girls, although this difference did not emerge as statistically significant.

The multidirectionality in gender effects and the variability in the gender of leaders of language change across different sociolinguistic variables seem to be related to the urban-rural dichotomy and the different social meanings associated with urban and rural variants. This dichotomy drives a contrastive gender ideology within this tight-knit speech community: girls are discouraged from sounding rough and local and encouraged to sound feminine and refined, while it is acceptable for boys to sound tough, masculine, and local. Thus, linguistic changes in the direction of variants that are indexed to urban identity, such as [?] and the urban vowels, are led and advanced by females who aspire to the qualities 
indexed to the urban variants, such as prestige, refinement, social mobility, and femininity. However, the contrastive gender ideology drives a reverse change in progress in the direction of the rural variants that are indexed to locality, masculinity, virility, and toughness. This reverse change isled and advanced by boys who aspire to such qualities.

In contrast to the phonological variables, the DMs are not indexed to specific social meanings or to the urban-rural dichotomy. In other words, they are not identified as local or supralocal in the community. In this case, a change in progress could not be confirmed. It is possible then that this lack of indexicality to specific social meanings or local-nonlocal result in age-graded variation, highly differentiated linguistic behavior between adults and children and reversed gendered linguistic behavior between the two generations. The statistically significant difference between children and adults and between mothers and father may suggest a change in progress in its initial stage led by adult females. If this is true, girls will be expected to advance the change. However, the non-significant gender difference between boys and girls and the use of more ?innu by boys than girls suggest otherwise. Hence, it appears that variants that have no urban-rural indexicality do not follow the same gendered leadership patterns as those variants that have very strong indexicality to urban or rural identities and the various social meanings associated with these identities.

These findings are significant because they suggest that only variants that are indexed to specific social meanings and identities can undergo a change in progress and show leadership by either gender depending on the social meanings associated with them. In contrast, variants that lack indexicality to social meanings and identities are less likely to show a clear change in progress or identifiable gender leadership.

Accordingly, future research should consider tackling questions such as these: Do these findings apply to other Arabic- and non-Arabic-speaking communities, including western- and non-western ones? Why do different variables pattern differently within the same community in relation to social factors such as gender and age? How can we reconcile the differences we have observed beyond the idea that different variables pattern differently (Eckert, 2008) across gender and age? Why does the effect of gender on linguistic variables vary/fluctuate among the same population? Further research is required on these and other variables to understand the observed gendered linguistic conflicts and other conflicting linguistic patterns and the socio-psychological factors that may affect these patterns in areas that are highly influenced by contact and the spread of urbanization in Syria, other Arab countries, and countries around the world.

\section{Endnotes}

${ }^{1}$ The variant [?] is characteristic of major urban centers in Syria, such as Damascus, Hims, Aleppo, Tartus, Hamah, and Latakia in addition to some regions to which [?] has spread and become highly prevalent. The variant [?] is also characteristic of many other major Arab cities, such as Cairo, Beirut, and Jerusalem. Hence, it has a special supralocal status not only within Syria, but also 
across many Arab countries.

2 ?af is the name given to [?] in Syrian Arabic, adopted from the pronunciation of qaf, changing the initial [q] to [?]. All spoken quotes are my translation of what speakers said in Arabic. All participants' names used in this paper are pseudonyms.

\section{Rania Habib}

Syracuse University, USA

ORCID Number: 0000-0002-6588-6442

Email: rhabib@syr.edu 


\section{References}

Abd-el-Jawad Hassan R. (1986). 'The emergence of an urban dialect in the Jordanian urban centers'. International Journal of the Sociology of Language, 61 (1):53-63.

Al-Batal, Mahmoud. (1994). 'Connectives in Arabic diglossia: The case of Lebanese Arabic'. In Mushira Eid, Vicente Cantarino and Keith Walters (Eds.), Perspectives on Arabic linguistics VI, 91-120. Amsterdam/Philadelphia: John Benjamins.

Al-Essa, Aziza. (2009). 'When Najd meets Hijaz: Dialect contact in Jeddah'. In Enam Al-Wer and Rudolf de Jong (eds.), Arabic dialectology, 203-222. Amsterdam: Brill.

Al-Ma'louf, Hanna Elias. (2008). Tariq Al-Hayat wa Hayat T-Tariq 'Life Road and Road Life'. Hims, Syria: Al-Sha'ar li-TTiba'a.

Al-Nassir, A. A. (1993). Sibawayh the phonologist: A critical study of the phonetic and phonological theory of Sibawayh as presented in his treatise AlKitab. London: Kagan Paul International.

Al-Wer, Enam. (2007). 'The formation of the dialect of Amman: From chaos to order'. In Catherine Miller, Enam Al-Wer, Dominique Caubet and Janet C.E. Watson (Eds.), Arabic in the city: Issues in dialect contact and language variation, 55-76. London: Routledge.

Andersen, Elaine S., Maquela Brizuela, Beatrice Dupuy and Laura Gonnerman. (1999). 'Cross-linguistic evidence for the early acquisition of discourse markers as register variables'. Journal of Pragmatics, 31:1339-1351.

Buchstaller, Isabelle. (2006). 'Diagnostics of age-graded linguistic behavior: The case of the quotative system'. Journal of Sociolinguistics, 10 (1):3-30.

Chambers, J. K. (2002). 'Dynamics of dialect convergence'. Journal of Sociolinguistics, 6:117-130.

Cowell, Mark W. (1964). A reference grammar of Syrian Arabic. Washington, DC: Georgetown University Press.

Daher, Jamil. (1998). 'Gender in linguistic variation: The variable (q) in Damascus Arabic'. In Elabbas Benmamoun, Mushira Eid and John McCarthy (Eds.), Perspectives on Arabic linguistics XI, 183-206. Amsterdam/Philadelphia: John Benjamins.

De Houwer, Annick. (2003). 'Language variation and local elements in family discourse'. Language Variation and Change, 15: 329-349.

Dermarker, Cynthia. (2014). 'French meets Arabic in Cairo: Discourse markers as gestures'. In Juliane Besters-Dilger, Cynthia Dermarkar, Stefan Pfänder and Achim Rabus (Eds.), Congruence in contact-induced language change: Language families, typological resemblance, and perceived similarity, 275-293. Berlin: De Gruyter.

Eckert, Penelope. (2008). 'Variation and the indexical field'. Journal of Sociolinguistics, 12 (4):453-476. 
Ferguson, Charles. (1959). 'Diglossia'. Word, 15(2):325-340.

Foulkes, Paul, Gerard J. Docherty and Dominic Watt. (2005). 'Phonological variation in child-directed speech'. Language, 8(1):177-206.

Gal, Susan. (1978). 'Peasant men can't get wives: Language change and sex roles in a bilingual community'. Language in Society, 7(1):1-16.

Germanos, Marie Aimee. (2010). 'From complementizer to discourse marker: The functions of Pənno in Lebanese Arabic'. In Jonathan Owens and Alaa Elgibali (Eds.), Information structure in spoken Arabic, 145-164. New York: Routledge.

Ghobrial, Atef N. (1993). Discourse markers in colloquial Cairene Egyptian Arabic: A pragmatic perspective. Unpublished Ph.D. dissertation, Boston University.

Habib, Rania. (2009). 'The syntax of the standard Arabic particles ?an and Panna'. In Kleanthes Grohmann and Phoevos Panagiotidis (Eds.), Selected Papers from the 2006 Cyprus Syntaxfest, 159-194. Newcastle-upon-Tyne: Cambridge Scholars Publishing.

Habib, Rania. (2014). 'Vowel variation and reverse acquisition in rural Syrian child and adolescent language'. Language Variation and Change, 26(1):45-75.

Habib, Rania. (2016a). 'Bidirectional linguistic change in rural child and adolescent language in Syria'. dialectologia, 16: 117-141.

Habib, Rania. (2016b). 'Identity, ideology, and attitude in Syrian rural child and adolescent speech'. Linguistic Variation, 16(1):34-67.

Habib, Rania. (2017a). 'Children's deviation in the acquisition of variable linguistic gender patterns'. Macrolinguistics, 5(6):65-94.

Habib, Rania. (2017b). 'Parents and their children's variable language: Is it acquisition or more?' Journal of Child Language, 44(3):628-649.

Habib, Rania. (2021). 'The use of the discourse markers yasni and Pinnu: 'I mean' in Syrian Arabic'. Journal of Pragmatics, 178:245-257.

Hill, Sara E. and Ross Flom. (2007). '18- and 24-month-olds' discrimination of gender-consistent and inconsistent activities'. Infant Behavior and Development, 30:168-173.

Hirschfeld, Lawrence A. and Susan A. Gelman. (1997). 'What young children think about the relationship between language variation and social difference'. Cognitive Development, 12: 213-238.

Holmes-Elliott, Sophie. (2016). 'Ladies first? Adolescent peaks in a male-led change. University of Pennsylvania Working Papers in Linguistics, 22(2): Article 10.

Ibrahim, Muhammad H. (1986). 'Standard and prestige language: A problem in Arabic sociolinguistics'. Anthropological Linguistics, 28(1):115-126.

Labov, William. (1994). Principles of linguistic change, volume I: Internal factors. Malden, MA: Blackwell.

Labov, William. (2001). Principles of linguistic change, volume II: Social factors. Malden, MA: Blackwell.

Labov, William. (2007). 'Transmission and diffusion'. Language, 83(2):344-387. 
Labov, William. (2010). Principles of linguistic change'. volume III: Cognitive and cultural factors. Malden, MA:Wiley-Blackwell.

Labov, William. (2013). 'Preface: The acquisition of sociolinguistic variation'. Linguistics, 51(2):247-250.

Marmorstein, Michal. (2016). 'Getting to the point: The discourse marker yaSni (lit. "it means") in unplanned discourse in Cairene Arabic'. Journal of Pragmatics, 96:60-79.

Miller, Catherine. (2005). 'Between accommodation and resistance: Upper Egyptian migrants in Cairo'. Linguistics, 43(5):903-956.

Miller, Karen. (2013). 'Acquisition of variable rules: /s/- lenition in the speech of Chilean Spanish-speaking children and their care givers'. Language Variation and Change, 25:311-340.

Milroy, James and Lesley Milroy. (1985). 'Linguistic change, social network and speaker innovation'. Journal of Linguistics, 21:339-384.

Mughazy, Mustafa. (2003). 'Discourse particles revisited: The case of wallaahi in Egyptian Arabic'. In Dilworth Parkinson and Samira Farwaneh (Eds.), Perspectives on Arabic linguistics XIII, 3-29. Amsterdam/Philadelphia: John Benjamins.

Omari, Osama and Aziz Jaber. (2020). 'Emphasis, manner, and voice in urban Jordanian Arabic: Linguistic and extralinguistic interactions'. International Journal of Arabic-English Studies, 20(1):7-18.

Owens, Jonathan and Trent Rockwood. (2008). 'YaSni: What it (really) means'. In Dilworth Parkinson (Ed.), Perspectives on Arabic linguistics XXI, 83-114. Amsterdam/Philadelphia: John Benjamins.

Poplack, Shana. (1978). 'Dialect acquisition among Spanish-English bilinguals'. Language in Society, 7:89-103.

Rieschild, Verna. (2011). 'Arabic ya'ni: Issues of semantic, pragmatic, and indexical translation equivalence'. Intercultural Pragmatics, 8(3):315346.

Roberts, Julie. (1997). 'Acquisition of variable rules: A study of (-t, d) deletion in preschool children'. Journal of Child Language, 24(2):351-372.

Roberts, Julie. (2005). 'Acquisition of sociolinguistic variation'. In Martin J. Ball (Ed.), Clinical sociolinguistics, 153-164. Oxford: Blackwell.

Schilling-Estes, Natalie and Walt Wolfram. (1994). 'Convergent explanation and alternative regularization patterns: Were/weren't leveling in a vernacular English variety'. Language Variation and Change, 6:273-302.

Smith, Jennifer, Mercedes Durham and Hazel Richards. (2013). 'The social and linguistic in the acquisition of sociolinguistic norms: Caregivers, children, and variation'. Linguistics, 51(2):285-324.

Tagliamonte, Sali. (2005). 'So who? Like how? Just what? Discourse markers in the conversations of young Canadians'. Journal of Pragmatics, 37:18961915.

Trudgill, Peter. (1972). 'Sex, covert prestige and linguistic change in the urban British English of Norwich'. Language in Society, 1(2):179-195. 
Walters, Keith. (1991). 'Women, men, and linguistic variation in the Arab world'. In Bernard Comrie and Mushira Eid (Eds.), Perspectives on Arabic linguistics III, 199-229. Amsterdam/Philadelphia: John Benjamins.

Wolfram, Walt, Phillip Carter and Beckie Moriello. (2004). 'Emerging Hispanic English: New dialect formation in the American South'. Journal of Sociolinguistics, 8(3):339-358. 